\title{
The European Paradigm of Social Exclusion
}

\section{Stefan Bernhard}

\section{Introduction}

The implementation of the Open Method of Coordination (OMC) in the field of European social policy has been a major turning point for European Union (EU) integration in recent years. By setting common European objectives and leaving their attainment to Member States, the OMC was initiated to trigger learning processes on the national level. The method has sparked tremendous scientific research (see e.g. Hodson/Maher 2001, Heritiér 2002, Mosher/Trubek 2003, Jacobsson 2004). However, scholars diverge when it comes to evaluating the method's potential for policy change. Those emphasising learning are more optimistic (Rhodes/Goetschy/Mosher 2000, de la Porte/Pochet/Room 2001) than those who question its effectiveness due to the lack of sanctioning mechanisms (Scharpf 2000, 2002, Schäfer 2005).

Notwithstanding disagreement, both assessments rely on the assumption that the OMC actually works as a decentralised learning process, implying that no paradigm concerning social exclusion exists at the European level. However, it is time to question this taken-for-granted assumption. It is argued that the OMC disseminates a European paradigm of social exclusion. The institutions established in order to enable voluntary learning by national and sub-national actors constitute in fact the infrastructure for the dissemination of an European paradigm of social exclusion. It is argued that streamlining the OMC process further carves out these basic characteristics, thereby intensifying the effects of paradigm dissemination triggered by policy coordination with the OMC.

The article is divided into four sections. The following section gives a brief overview over the literature on the OMC focussing on their divergent points of departure. Learning, effectiveness and constructivism are presented as three dominating approaches. The third section develops a theoretical concept following the constructivist approach. It is argued that the OMC is legitimised as a learning process; but it also works as legitimising structure for a European paradigm within a social field. The fourth section works out core features of the European paradigm of social exclusion against the background of a complex and reductionist ideal type of social exclusion. The conclusion states that the OMC can only be fully described as a combination of two processes: learning and paradigm dissemination.

\section{Three perspectives on the OMC}

The inception of the "new" OMC at the Lisbon Summit (Presidency Conclusions Lisbon 2000: paragraph 7) has initiated extensive scientific research from the very beginning (Rhodes/ 
Goetschy/Mosher 2000, Hodson/Maher 2001, de la Porte/Pochet/Room 2001). In general, the different approaches can be grouped into three different strands, each following certain over-arching research questions and (more or less implicit) axioms.

The first perspective tackles the OMC with respect to its effectiveness for improving national policies. The over-arching question is, whether the method will bring about policy transformation. The approach is firmly embedded in a "rationalist" perspective (as opposed to a constructivist one), assuming self-interested participants with fixed interests and thin institutions that act as an intervening variable. Politics is mainly about decision-making and negotiating (Checkel 1999, Christiansen/Jorgensen/Wiener 1999, Wiener/Diez 2004). Scholars advocating this perspective predominantly take a sceptical view concerning the OMC's potential. Theoretically, they point to the lack of sanctions (Scharpf 2000, 2002) that keeps the process a captive of political interests (Chalmers/Lodge 2003).

The second perspective starts from the institutional structure of the OMC and focuses on the learning potential of the method. It interprets the $\mathrm{OMC}$ as a classic example of new modes of governance thereby confronting it with "old modes" that are based on sanctioning mechanisms (Hodson/Maher 2001, Trubek/Trubek 2003). Accordingly, what looks like a drawback from the perspective of effectiveness appears to scholars rooted in the learning perspective as opportunity for "bottom-up learning" (de la Porte/Pochet/Room 2001: 305). The idea of learning is most elaborated with reference to the 'democratic experimentalism' (Dorf/Sabel 1998, Sabel/Zeitlin 2003, Eberlein/Kerwer 2004). Contrary to the first approach, the learning perspective does not consider learning as contradictory to political interests.

The constructivist perspective complements the first two approaches with a third one, which goes beyond the idea of learning and sanctioning as motors of change. It shares the interest in processes with the learning perspective mentioned above. However, it looks for effects beyond explicit learning processes. Prominently, Jacobsson (2004) introduced "discursive regulatory mechanisms" (ibid: 259) of the OMC like common language or the development of a common knowledge base. Unlike learning processes, these mechanisms are "likely to fulfil a steering function both in terms of policy thinking and administrative and national-policy practice." (ibid: 366 , see also Trubek and Trubek 2005, Zeitlin 2005b). This article is based on a constructivist perspective. It is argued that the conflict of learning and sanctioning, which is perceived to overshadow the process, is not a default of the OMC but its very prerequisite.

\section{The OMC as legitimised and legitimising structure}

\section{A legitimated structure of policy coordination}

The legitimacy of the OMC relies on two assumptions. The first assumption refers to its potential. It is assumed that the process can help to improve national strategies against poverty and social exclusion. The second assumption concerns the process that leads to these improvements. As the $O M C$ rests on learning instead of sanctioning, the story goes, the principle of subsidiarity is met while at the same time common objectives are pursued. European Institutions and scholars share these assumptions alike (see for example Council of the European Union 2000a, CEC 2003c, Eberlein/Kerwer 2002).

Learning within the OMC - as understood in this context - refers to a very specific way of learning, which basically follows the idea of 'democratic experimentalism' (Dorf/Sabel 1998). It is a highly decentralised process, which starts with the voluntary agreement of constituencies to enter into a process of mutual learning. Based on this agreement a "governance council" (ibid: 316) gathers and distributes information, which prepares the ground for mutual learning 
in the group of participants. Since non-participation creates clear disadvantages in terms of performance, the process does not need strong coercive mechanisms.

An important principle behind this process is the division of labour between the central level of the governance council and the decentralised level of the participants. At the central level information is gathered, distributed and discussed, and best practices are identified in a peer group. However, policy choices and responsibility remain with the constituencies. Taken together learning according to the democratic experimentalist idea presupposes a set of procedural requirements that are enshrined in the formal institutional structure of the OMC through the NAP, Peer Reviews and the Joint Report (Bernhard 2005a).

Clearly, OMC diverges from this model in several respects. Most importantly, Member States did not join the process voluntarily one by one, but as a group. Consequently, they cannot drop out individually whenever they like. This modification is the reason why Member States are eager to enlarge their discretion within the OMC, especially by curtailing the dynamics of benchmarking and peer pressure at the European level. ${ }^{1}$ It offers to Member States the possibility not to comply with the procedural requirements in compensation for the missing option to exit it.

To sum up we can say that the structure of the OMC offers a double safety net for Member State autonomy. First, as a learning process it refrains from instruments of (hierarchical) sanctioning. Second, since dropping out of the process is impossible, room for weakening and evading the demanding requirements for benchmarking and peer pressure is assured. The OMC is only legitimised because this safety net exists. The solemn affirmation to move towards common objectives through a process of mutual learning comes at the price of this far-reaching controllability of the process. Rationalist are right in stating that the process is deliberately moulded to ensure full member state control and to avoid the institutionalist integration dynamics experienced in other policy areas (Schäfer 2005). Paradoxically, the process of policy coordination is legitimised only because its effectiveness (as a learning process) can be undermined at any time. The $O M C$ is self-commitment without self-bounding. Literature on the OMC has reflected on this by locating the method in the twilight of learning and politics (see section 2). A growing body of empirical observations clearly supports this judgement by showing how learning is impeded as soon as "political" interests become relevant. Still, these impediments are considered to interfere, threaten or hamper the "pure" process of mutual learning. The opposite is the case. The OMC is not hampered by political interferences; it is based on their possibility. It is legitimised as a structure that guarantees vast autonomy for Member States. Locating the method as a learning process within a political surrounding therefore constitutes the theoretical starting point, not the endpoint of this analysis.

\section{A paradigm-legitimising structure}

The opposition of learning and politics is embedded in the rationalist axiom. It concentrates on what, following Bourdieu, could be called the "materialist" aspect of politics, neglecting its symbolic components (Bourdieu 1993 [1980]). According to Bourdieu the social sphere is organized into social fields (Bourdieu 2001 [1992], Bourdieu/Wacquant 1992). Fields are constituted by paradigms that stretch over a relative dense setting of institutions and actors and structure their interactions in a meaningful way. The term 'paradigm' refers to commonly shared perceptions, evaluations and ideas that can be more or less elaborated as theories, narrations or the like (Bourdieu 1976). ${ }^{2}$ Paradigms are "dominating" (Bourdieu 1996) as they implement a particular perspective as "natural" and without question for actors involved in the field (Bourdieu 1992).

Analytically, fields can be divided into a material dimension, referring to the distribution of valued objects, and a symbolic dimension, referring to the hierarchy of appreciation of these 
objects (Bourdieu 2001 [1992], Schwingel 1993). The relative importance of the material and the symbolic dimension vary across fields with the political field being of highly symbolic nature. Symbolic power takes the form of "performative discourses" (Bourdieu 1998 [1994]) that construct the things they pretend to describe. Since all political fields establish paradigms, political action is based on shared perceptions, evaluations and ideas that underlie strategies, decision-taking and bargaining.

This approach to politics is a viable complement to the rationalist perception of the OMC. The $O M C$ establishes a field of relative density in terms of actors and institutions, which is structured by a European paradigm of social exclusion. It is a political field, which implies that the symbolic dimension is of particular importance. The importance is heightened yet again in the case of new modes of governance, because they are equipped with comparatively weak battlegrounds for material struggles, typically characterising decision-making procedures.

Seen from this angle, the method is primarily not a learning process lacking sanctions, but an infrastructure for the dissemination of a paradigm. Learning is based on information, dissemination on the existence of a paradigm. The two dynamics can be distinguished in two respects. First, learning within the OMC is a highly decentralised process whereby information is offered to Member States and it is up to them to decide what they do with it and if they do anything with it all. Dissemination in contrast implies a centre that puts forward a certain paradigm. Information gathering and distribution will not be neutral, but "bound" in the sense that they reflect the contours of this paradigm. ${ }^{3}$

Second, learning and dissemination conceptualise the participants in differing ways. As argued above, learning takes a rationalist perspective and assumes that participants either choose to learn or to seal themselves from the process (which also implies that they are able to do so). Dissemination presupposes participants that are susceptible to the symbolic influence of the paradigm during the course of the process. The OMC affects their horizon of perceptions and ideas. While learning is addressed to "Member States", dissemination also influences the worldview of individuals by shaping discourse frames (see Jacobsson 2004, Armstrong 2003, Zeitlin 2005b).

Different dynamics of change are implied by the learning and the dissemination model. Learning is about information processing, dissemination about paradigm implementation. It is important to note that learning and dissemination do not exclude one another. Processes of paradigm dissemination may well be accompanied by learning dynamics. However, learning will take place within a certain horizon of available possibilities that is established and transformed through the dynamic of dissemination. Learning is bound to the extent that the respective paradigm is conceptually open. A paradigm can be considered to be conceptually open when it is possible to include a great variety of diverging ideas, solutions or cause-effect relationships in it. It will be conceptually closed when this possibility is eliminated so that but one coherent idea is available (see section 4). The higher paradigm closure becomes, the fewer are the options for learning.

Switching from (unbound) learning to dissemination does change the prevalent dynamic of the $O M C$ and with it the functioning of its institutions. Table 1 shows how the formal institutions of the OMC are supposed to work according to the legitimate learning process and how they work as a paradigm-legitimising structure.

\section{Table 1: The OMC as legitimate and legitimising process (see Annex)}

On the left hand side the institutions are presented according to the idea of a decentralised learning process. In the presence of a European paradigm of social exclusion the same institutions work in a different way, becoming an infrastructure of dissemination. This is presented on the right 
hand side. The table shows how switching the theoretical framework impacts on the perception of $O M C$ institutions. The question whether the OMC actually functions as a dissemination process can only be answered by empirically showing that a European paradigm does exist. If this can be demonstrated, theoretical consequences will be unavoidable.

\title{
The European paradigm of social exclusion
}

\author{
The contours of social exclusion
}

The notion of social exclusion is an "essentially contested concept" (Connolly 1974: 10). At the European level two concepts of social exclusion can be identified as ideal types. ${ }^{4}$ The complex concept, on the one hand, pictures social exclusion as a process and as a situation, relating to a considerable disruption between those inside and those outside society. It meets scientific requirements for the concept of social exclusion, namely multidimensionality, process and relational character (Kronaver 2002). According to this perspective social exclusion is a phenomenon yet to be fully captured, which involves the need for further research.

The reductionist concept of social exclusion at the opposite end has been stripped of this multidimensionality and establishes a predominant employment-nexus, putting paid work and economic prosperity at the centre of the fight against exclusion. Consequently, activation policies dominate the reform agenda, be it in the guise of an activating welfare state "increasing labour supply" or in the guise of an activating labour market policy "drawing" (CEC 2005b: 38) people inside the labour market.

The two ideal types tell different stories about what social exclusion actually is (problem description), what the main circumstances behind the phenomenon are (cause-effect relationships) and what kind of action is needed as appropriate answer (remedy). The following table summarizes the main properties of the ideal types as "narrative patterns" (Viehöver 2001).

Table 2: Complex and reductionist ideal types of social exclusion (see Annex)

These ideal types can serve as a interpretational background against which the contours of the European paradigm stand out more clearly. The European paradigm comprises three aspects: employment, income and education. ${ }^{5}$ They are firmly routed in the Primary Indicators, the Joint Reports and Common Objectives. These dimensions dominate the perception of social exclusion in terms of problem description, cause-effect relationships and potential remedies.

The problem description is based on common indicators. Out of 18 primary and secondary indicators agreed upon on a European level 14 are related to income or employment (Kröger 2004), and two are dealing with education and health. Progress in the development of further indicators (i.e. non-monetary ones) is hampered by Member States disagreement (SPC 2003b). Although these primary indicators are to be complemented by national ones, their one-sidedness raises questions about the multidimensionality of the European approach, especially bearing in mind that they are introduced as relating to the "most important elements in leading to social exclusion" (Council of the European Union 2000b: 3).

The description of cause-effect relationships concentrates around the same dimensions. They form a quite dense narrative pattern, establishing causal links between these dimensions and social exclusion. Employment is considered to be the best way out of exclusion, while at the same time being the most reliable indicator of the phenomenon. It is supported by the variables education 
and social protection systems. Income, too, functions as an indicator and a remedy at the same time. Still, since it is not as consequently interwoven in the web of causal relationships, it is not as important as remedy. Education is addressed in the context of the capacity to join the labour market. As a supporting variable it complements employment on the key route out of social exclusion. Increasingly, reforming social security systems enters the picture, likewise supporting the labour market by creating incentives to work.

The European paradigm of social exclusion is embedded in the Lisbon Strategy, which is centred on the idea of a transition to a knowledge-based economy and society. In consequence of this transition, new challenges and threats emerge: "The new knowledge-based society offers great possibilities for reducing social exclusion, both by creating the economic conditions for greater prosperity and by opening up new ways of participating in society. The emergence of new information and communication technologies constitutes an exceptional opportunity, provided that the risk of creating an ever-widening gap between those who have access to the new knowledge and those who do not is avoided." (CEU 2002: 6). Response from the political side is necessary, because in the "changing world of work economic progress does not automatically bring benefits for all." (CEC 2000a: 7). The stake is enormous, because a "two tier knowledge based society" (CEC 2000c: 22) where social exclusion is exacerbated, constitutes a potential development. So, according to the narrative pattern macro-societal changes are identified and are perceived to require immediate and appropriate reaction from political actors. Political responsibility is immense, since the direction of change (knowledge-based economy and society), risks (two-tiered society) and opportunities (inclusion for everyone), and remedies (reform) are all well known. There should be no hesitation. Political reform is just a matter of implementation, not of general design or direction.

Thus, Member States performances can be compared according to their advances in the direction desired on the scale of reform. While this is avoided in any obvious fashion, a background for such an assessment is subtly installed through identifying key policy priorities (i.e. CEC/CEU 2004: 8). ${ }^{6}$ This explains the remarkable rhetoric of urgency accompanying the presentation of the reform agenda: "The Lisbon strategy sets out a roadmap for the European Union's economic, social and environmental renewal in the medium to long term. (...) The strategy has now reached a decisive moment. (...) It is a choice between moderate growth, continuing unemployment, limited cohesion and slow progress in curbing unsustainable trends, or raising the Union's potential and sustaining it over the next seven years to keep the Lisbon goals within reach. A choice between following or leading." (CEC 2004a: 9).

The following diagram 1 depicts the narrative pattern surrounding the European paradigm of social exclusion.

\section{Diagram 1: The narrative pattern of the EU paradigm on social exclusion (see Annex)}

The illustration shows the general trend towards the knowledge-based society, which is perceived to be unstoppable. Global competition and technological development are the main driving forces behind this dynamic. They change the structure of the labour market (for example by creating shifts between sectors of employment or fostering new forms of work) and the job profile (for example increasing importance of (T-related skills). This development is accompanied by a parallel ageing of society and a change in family structure that are considered to be a burden for social protection systems. These factors produce an urgent need for encompassing reform. The appropriateness of reform will be decisive for future development. The path of political sluggishness will lead to an increasing social and economical divide (two-tiered society). The path of appropriate reform will bring about a knowledge-based society that "offers tremendous potential for reducing social 
exclusion, both by creating the economic conditions for greater prosperity through higher levels of growth and employment, and by opening up new ways of participating in society." (Council of the European Union 2000a: Paragraph 32).

The core of the European paradigm of social exclusion concentrates on the causal link of three components mentioned above. Disconnected from these three factors are income and rights that do not form part of the reform agenda. Income is considered to be important, but it is not introduced as means against social exclusion in a permanent fashion. Access to rights is also persistently mentioned in the OMC process. However, rights are most of the time related to a whole set of "fundamental rights" (CEU/CEC 2002: 11), to which access should be granted, without addressing them individually or introducing them into the web of causal links.

Finally, the inclusive society hinges on a benevolent economic development made possible by sound macro-economic policies. Inclusive society, economic development (that is growth) and employment constitute the elements of a triangle that is imbalanced. Growth, as is constantly asserted, is a precondition for employment as well as for an inclusive society. This link is supported by the causal explanation that growth contributes to employment and that employment is the best way out of social exclusion. This hierarchy is a predecessor of the total merge of employment and social inclusion policies to be found in the reductionist ideal type (see for example CEC 2002a: 14).

It belongs to the key characteristics of the European paradigm of social exclusion, first, that it is firmly rooted in the analysis of overall macro-societal change and, second, that the appropriate answer is considered available. Since the count-down has now been started, it does not only have to be the right type of reform but it also has to be implemented immediately. It is this image of unstoppable ongoing change and high urgency that, alongside the clear emphasis on employment, education and income, attach a paradigmatic quality to the European perception of social exclusion.

Referring to the two ideal types addressed above, we can see that official documents within OMCind borrow from both of them in a particular way. While they acknowledge the multidimensionality and process-nature of social exclusion, they focus on only a few dimensions, pressing for reform in the areas of employment, education and social security systems. Metaphorically speaking the European paradigm functions like a funnel, taking on board a great variety of dimensions, causes and policy approaches, but accentuating only a few of them. In so doing, the paradigm takes the middle ground between the complex and the reductionist alternative. Just like the complex version its problem description uses a rather wide focus. Where indicators do not meet theoretical needs further dimensions are at least appealed to. Just like the reductionist counterpart it adopts clear-cut cause-effect attributions that entail the necessity for urgent and appropriate reforms.

As paradigms are underlying structures of meaning that are not elaborated as such (for example as explicit theory) it is permanently vulnerable to shifts in meaning. The multidimensional nature of "social exclusion" renders this paradigm particularly susceptible to adding new components (i.e. dimensions) or re-evaluating existing ones. ${ }^{7}$ Changing actor coalitions and institutional restructuring (see below) play a significant role in this respect.

The conceptual effect of streamlining

The position of the European paradigm between the two poles is far from fixed. Prior to the inception of OMCincl the multiplicity of dimensions were more evenly balanced and therefore closer to the complex ideal type as is now the case. Further conceptual shifts are likely, especially in consequence of 'streamlining' the social OMCs currently under way. Streamlining brings about 
two changes concerning the concept of social exclusion. First, it reduces the room for conceptual complexity in the Joint Reports. Second, it enforces the links between the three different processes (of pension, health care and care for the elderly and social inclusion) to one another and, most importantly, tightens the connection of all processes to the Lisbon goals of growth and employment. Both changes have the potential to impact on the concept of social exclusion, pushing it towards the reductionist pole of the ideal type dimension.

The second and revised Communication on "streamlining" the three social OMC processes lays out the details for merging the social OMC process into one. Transition to the new mode of coordination starts with the first integrated national strategies to be issued in September 2006, covering two years (CEC 2005). Later, these plans will cover a three years period. The Commission compiles a Joint Report in preparation of the Spring Councils. In years where national strategies are submitted, the report will summarize main issues and trends, assess Member States' progress in reaching the common objectives and review the connection to Lisbon goals (compare ibid: 7). ${ }^{8}$ In intervening years, where no national strategies are provided, the OMC "will concentrate on in-depth analyses of specific issues and on disseminating policy findings." (ibid: 8). A detailed Outline for the National Reports on strategies for social protection and social inclusion (CEC 2006) by the Commission assures that agenda setting for these reports is a European level issue.

This new structure of the Joint Reports considerably limits the room for conceptual complexity simply by reducing the issue of social exclusion from a 250 page report to one theme among three to be dealt with in no more than 12 pages. Drawing from the first two 'short' Reports on Social Protection (covering the years 2005 and 2006), it is beyond doubt that streamlining comes at the cost of conceptual complexity. The streamlined report will push aspects of secondary importance (for example housing and health) to the side and banishes aspects of tertiary importance completely. Although they form part of the definition of social exclusion and of the common objectives, the issues "sport", "leisure", "access to culture" and "social networks" are not even referred to a single time in the Joint Reports of 2005 and 2006. Hence, streamlining will tremendously sharpen the contours of the European paradigm of social exclusion.

The second pressure towards conceptual downsizing stems from the reformulation of the Common Objectives. Even though the three social strands preserve some independence within the streamlined process, they are summoned under "new integrated common objectives" (CEC 2005: 4). These are subdivided into overarching objectives and strand-specific objectives. The overarching objectives set out the promotion of "social cohesion and equal opportunities for all" as first goal, accompanied by two other goals demanding a close interaction with other Lisbon objectives "on achieving greater economic growth and more and better jobs and with the EU's Sustainable Development Strategy" (ibid: 5) and improving governance, respectively. The subordinate objectives concerning solely the social inclusion strand do now link labour market integration to social inclusion causally. True, in the earlier objectives employment was embedded in causal attributions, too. However, these links established employment as an important subordinate goal, not as a direct means to generate social inclusion (see CEU 2002: 10). Above this, the former objective "Mobilising all relevant bodies" lacks in its new version any hint at the "people suffering exclusion" (ibid: 12).

Strengthening the employment-nexus and concomitantly further neglecting multidimensionality follows the road of reducing conceptual complexity that distances the European paradigm further from the conceptually open ideal type. Streamlining supports this dynamic by strengthening the need to carve out a few most important issues and by taking away the basis for elaborating on less important ones. Establishing the goal of economic growth as issue of overriding importance deprives social inclusion of its status as an end in itself. Hence, in terms of paradigm density streamlining social OMC will most likely support the development of an ever closer European model of social exclusion. 


\section{Conclusion}

Scholars, participants and European Institutions share the conviction that OMCincl is a learning process. For some this is a failure that has to be corrected, for others it is the very essence of its strength. However, researchers increasingly acknowledge that this is not all what should be discussed. They stress the existence of mechanisms beyond and prior to learning and sanctioning and in doing so, they leave the terrain of rationalist analysis and set out for a constructivist approach to the OMC.

This article joins in their effort. It is argued that policy coordination in the framework of the $O M C$ does establish a social field with a European paradigm of social exclusion at its centre. Generally speaking, the paradigm is organized around the idea that employment, education and income are the most important dimensions for social exclusion and that employment is the place to apply the lever for inclusion.

These empirical findings have theoretical consequences. Since a paradigm dominates the field of policy coordination the OMC cannot solely be viewed as a more or less effective structure for mutual learning. Instead, the method is an infrastructure for the dissemination of the European paradigm. The OMC functions in a different way than it is supposed to: It is legitimised as a process of mutual learning, but in fact it constitutes an institutional set-up that legitimises a paradigm. The two sides refer to different dynamics. Learning is based on an unbiased exchange of information and on the willingness to leave strategic-political considerations (temporarily) to the side. Dissemination in fields, on the contrary, is an instance of symbolic power (Bourdieu 2001). Its dynamic is based on the subtle implementation of a horizon of ideas, of theories about cause and effect, and of a conceptual room for reforms. While learning is based on the generation of information, dissemination grounds on the selection of information.

It is therefore theoretically promising to conceptualise the process anew. The OMC is as much about the implementation of a paradigm in the European field of social inclusion as it is about policy learning between Member States. There is reason to believe that it is even more successful regarding the former as it is regarding the latter. This success, however, is based on the misconception that the process will either lead to learning, or be mere paper work. As long as the difference between the legitimated and the legitimising process is maintained, the European paradigm of social exclusion can unfold.

\section{Notes}

1) Literature on $O M C$ tends to draw a distinction between learning and benchmarking that does not exist in 'democratic experimentalism'. Whereas learning is solely about the exchange of information, benchmarking has to master problems of power relations (Mabbett 2004). Learning within 'democratic experimentalism', however, is learning-by-monitoring. As participation is voluntary, benchmarking does not take the role of hierarchy but, on the contrary, is a tool of information distribution (Dorf/Sabel 1998: 287) and of "questioning of routines" (ibid: 316). (Normatively) presupposing the will to learn, benchmarking is never perceived as a threat to autonomy and therefore does not engender power conflict between central agency and constituencies.

2) "Paradigm" (Kuhn 1976) replaces Fligstein's term "conception of control" (2001) and Bourdieu's term "doxa" and orthodoxy, respectively (Bourdieu 1976).

3) For reason of distinctiveness between rationalist and constructivist conceptions these bound processes are not referred to as "learning" although they could be described as such in a very broad understanding of the term (see for instance Checkel 1999). The term "learning" as used in this article rather sticks to the Democratic Experimentalist understanding, which does attach a sense of deliberate and voluntary action to it. 
4) Ideal types are understood in the sense of Max Weber. They are based on empirical phenomenon but are focussed and abstracted versions of these incidences. They serve interpretative purposes.

5) The following argument is based on a qualitative content analysis (Glaser/Strauss 1998) and makes use of the computer programme Atlas ti.. It concentrates on documents dealing with the $\mathrm{OMC}$ in the area of social inclusion, and encompasses above this documents prepared for the Spring Councils in the framework of the Lisbon Strategy.

6) The issue of priority setting is particularly strong for new Member States. Here the declared aim is to assist in the further development of social inclusion policies by identifying key priorities for the future (CEC 2004b: 8).

7) Different actors try to push the paradigm in divergent directions. Some, especially civil society actors like the EAPN, adhere to a rather complex model of exclusion. Others, most prominently the authors within the European Commission preparing the documents to the Spring Councils, put forward a reduced understanding of social exclusion. Each side has different access channels to the paradigm, for example the former use of the Community Action Programme to assure financial assistance and scientific research on the issue, the latter make their voice heard through the framework of the Lisbon Process (see section 4.4).

8) The Joint Report on Social Protection and Social Inclusion 2006 is already organised according to this structure (CEC 2006a).

\section{References}

Armstrong, K. A. (2003) 'Tackling social exclusion through OMC: Reshaping the boundaries of EU governance' in State of the Union: Law, Politics and Society, Vol. 6, edited by T. Börzel and R. Cichowski, Oxford, Oxford UP.

Atkinson, A. B. (2002) 'Social Inclusion and the European Union' Journal of Common Market Studies, 40, 625-643.

Atkinson, Anthony B., Eric Marlier and Brian Nolan (2004) 'Indicators and Targets for Social Inclusion in the European Union.' Journal of Common Market Studies, 42, 47-75.

Atkinson, R. and S. Davoudi. (2000) 'The Concept of Social Exclusion in the European Union: Context, Development and Possibilities' Journal of Common Market Studies, 38, 427-448.

Baver, Michael W. (2002). "Limitations to Agency Control in European Un ion Policy-Making: The Commission and the Poverty Programmes." Journal of Common Market Studies Vol. 40:381-400.

Bernhard, Stefan. (2005a) 'Sozialpolitik im Mehrebenensystem. Die Bekämpfung von Armut und sozialer Ausgrenzung im Rahmen der Offenen Methode der Koordinierung', Berlin: Wissenschaftlicher Verlag Berlin.

- (2005b) 'Die Offene Methode der Koordinierung als Prozess von Lernanreizen - Zu Theorie und Praxis der europäischen Inklusionsstrategie' BACES Discussion Paper No. $8 / 2005$.

Borrás, S. and K. Jacobsson (2004) 'The open method of co-ordination and new governance patterns in the EU' Journal of European Public Policy, 11, 185-208. 
Bourdieu, P. (1976) 'Entwurf einer Theorie der Praxis auf der ethnologischen

Grundlage der kabylischen Gesellschaft', Frankfurt a.M., Suhrkamp.

- (1992) 'Die verborgenen Mechanismen der Macht enthüllen' in Steinrücke M. (eds) Die verborgenen Mechanismen der Macht, Hamburg, VSA-Verlag.

— (1993) [1980]. Soziologische Fragen, Frankfurt a.M., Edition Suhrkamp.

— (1998) [1994] Praktische Vernunft. Zur Theorie des Handelns, Frankfurt a.M., Edition Suhrkamp.

- (2001) [1992] Das politische Feld. Zur Kritik der politischen Vernunff', Konstanz, UVK.

- (2001) Das politische Feld. Zur Kritik der politischen Vernunft, Konstanz, UVK.

Bourdieu, P. and L. Wacquant. (1992) An Invitation to Reflexive Sociology, Chicago, Chicago UP.

Chalmers, D. and M. Lodge (2003) The Open Method of Co-ordination and the Welfare State. ESRC Centre for Analysis of Risk and Regulation.

Checkel, J. T. (1999) 'Social construction and integration', Journal of European Public Policy, 6, 545-560.

CEC (2000a): Building an inclusive Europe. COM(2000) 79 final.

CEC (2000b): Social Policy Agenda. COM(2000) 379 final.

CEC (2000c): The Lisbon European Council - An Agenda of economic and socia renewal for Europe. DOC/00/7.

CEC (2000d): Proposal for a Decision of the European Parliament and of the Council Establishing a Programme of Community Action to Encourage Cooperation between the Member States to Combat Social Exclusion. COM(2000) 368 final.

CEC (2002a): The Lisbon Strategy - making change happen. COM(2002)14 final.

CEC (2002b): Community Action Programme to combat Social Exclusion (2002-2006). Proposals for Arrangements for selecting actions and organisations for Community support. Doc. SEP 6/02.

CEC (2003): Strengthening the social dimension of the Lisbon Strategy: Streamlining open coordination in the field of social inclusion. $\operatorname{COM}(2003) 261 / 2$ final. 
CEC (2004a): Commission Staff Working Paper in support of the report from the Commission to the Spring European Council in Barcelona. The Lisbon Strategy - making change happen. SEC(2002) 29/2.

CEC (2004b): Social Inclusion in the New Member States. A synthesis of the joint memoranda on social inclusion. SEC(2004) 848 final.

CEC (2005): Working together, working better: A new framework for the open

coordination of social protection and inclusion policies in the European Union.

$\operatorname{COM}(2005) 706$ final.

CEC (2006): Guidelines for preparing National Reports on Strategies for Social

Protection and Social Inclusion.

CEC/CEU (2002): Joint Report on Social Inclusion. Luxembourg OOPEC.

CEC/CEU (2004): Joint Report on Social Protection and Social Inclusion 2004. Luxembourg OOPEC.

CEU (2002): Objectives in the fight against poverty and social exclusion. 14110/00, SOC 470.

Christiansen T., K. E. Jorgensen and A. Wiener (1999) 'The social construction of Europe' Journal of European Public Policy, 6, 528-544.

Connolly, William E. (1974) The terms of political discourse, Lexington, D.C. Heath and Company.

Council of the European Union (2000a): Presidency Conclusions. Lisbon, 23 and 24 March 2000.

Council of the European Union (2000b): Presidency Conclusions - Annex. Nice 7., 8. and 9. December 2000. 'Fight against poverty and social exclusion - Definition of appropriate objectives'.

de la Porte, C., Pochet, P. and G. Room (2001) 'Social benchmarking, policy making and new governance in the EU', Journal of European Social Policy, 11, 291-307.

Dorf, M. C. and C. F. Sabel (1998) 'Constituion of Democratic Experimentalism', Columbia Law Review, 98, 267-473. 
Eberlein, B. and D. Kerwer (2004) New Governance in the European Union: A Theoretical Perspective', Journal of Common Market Studies, 42, 121-142.

Glaser, B. and A. Strauss. (1998) Grounded Theory. Strategien qualitativer Forschung, Bern: Verlag Hans Huber.

Hodson, D. and I. Maher (2001) 'The Open Method as a New Mode of Governance: The Case of Soft Economic Policy Co-ordination', Journal of Common Market Studies, 39, 719-46.

Heritiér, A. (2002) New Modes of Governance in Europe: Policy Making without Legislating?', Institut für Höhere Studien (IHS), Wien. March 2002.

Jacobsson, Kerstin (2004) 'Soft regulation and the subtle transformation of states: The case of EU employment policy', Journal of European Social Policy 14, 355-370.

Kröger, Sandra (2004) 'The commonly agreed indicators in the context of the OMC/incl.: Challenges and limitations', Governance, Law and Technology, Centre Marc Bloch, Berlin.

Kronaver, Martin (2002) Exklusion. Die Gefährdung des Sozialen im hoch entwickelten Kapitalismus, Frankfurt a. M., Campus.

Kuhn, Thomas (2002) [1976] Die Struktur wissenschafflicher Revolutionen, Frankfurt a.M., Suhrkamp.

Mosher, J. and D. M. Trubek (2003) 'Alternative Approaches to Governance in the EU: EU Social Policy and the European Employment Strategy' Journal of Common Market Studies, 41, 63-88.

Rhodes, M., J. Goetschy, and J. Mosher (2000). 'The Lisbon European Council and the Future of European Economic Governance' ECSA Review, 13, 2-7.

Sabel, C. F. and J. Zeitlin (2003) 'Active Welfare, Experimental Governance, Pragmatic Constitutionalism: The New Transformation of Europe' International Conference of the Hellenic Presidency of the European Union. 'The Modernisation of the European Social Model and EU Policies and Instruments', loannina, Greece.

Scharpf, F. W. (2000) 'Notes Toward a Theory of Multilevel Governing in Europe', MPIfG Disussion Paper 00/5, November 2000.

- (2002) ,Regieren im europäischen Mehrebenensystem - Ansaetze zu einer Theorie', Leviathan, 30, 65-92.

Schäfer, Armin (2005) Die neve Unverbindlichkeit. Wirtschaftspolitische Koordinierung in Europa, (Frankfurt a.M.: Campus).

Schwingel, Markus (1993) Analytik der Kämpfe. Macht und Herrschaft in der Soziologie Bourdieus, Hamburg, Argument-Verlag. 
SPC (2003): Opinion of the Social Protection Committee on the Commission's Communication, Strengthening the Social Dimension of the Lisbon Strategy: Streamlining Open Coordination in the Field of Social Protection. Brussels, September 2003.

Trubek, D. M. and L. G. Trubek. (2005) 'Hard and Soft Law in the Construction of Social Europe: the role of the Open Method of Co-ordination', European Law Journal, 11, 343-364.

Viehöfer, Willy. (2001) 'Diskurse als Narrationen', Keller, R., Hirseland, A. and W. Schneider (eds.), Handbuch Sozialwissenschaftliche Diskursanalyse. Theorien und Methoden, Opladen, Leske und Buderich, 177-206.

Wiener, Antje and Thomas Diez. (2004) European Integration Theory, Oxford, Oxford UP.

Zeitlin, Jonathan. (2005a) 'Conclusion: The Open Method of Coordination in Action: Theoretical Promise, Empirical Realities, Reform Strategy', Zeitlin, J., Pochet, P. and L. Magnusson, The Open Method of Coordination in Action: The European Employment and Social Inclusion Strategies, Brussels, P.I.E.-Peter Lang.

- (2005b) 'Introduction: The Open Method of Coordination in Question', Zeitlin, J., P. Pochet, and L. Magnusson, The Open Method of Coordination in Action: The European Employment and Social Inclusion Strategies, Brussels, P.I.E.-Peter Lang. 


\section{Annex}

Table 1: The OMC as legitimised and legitimising process

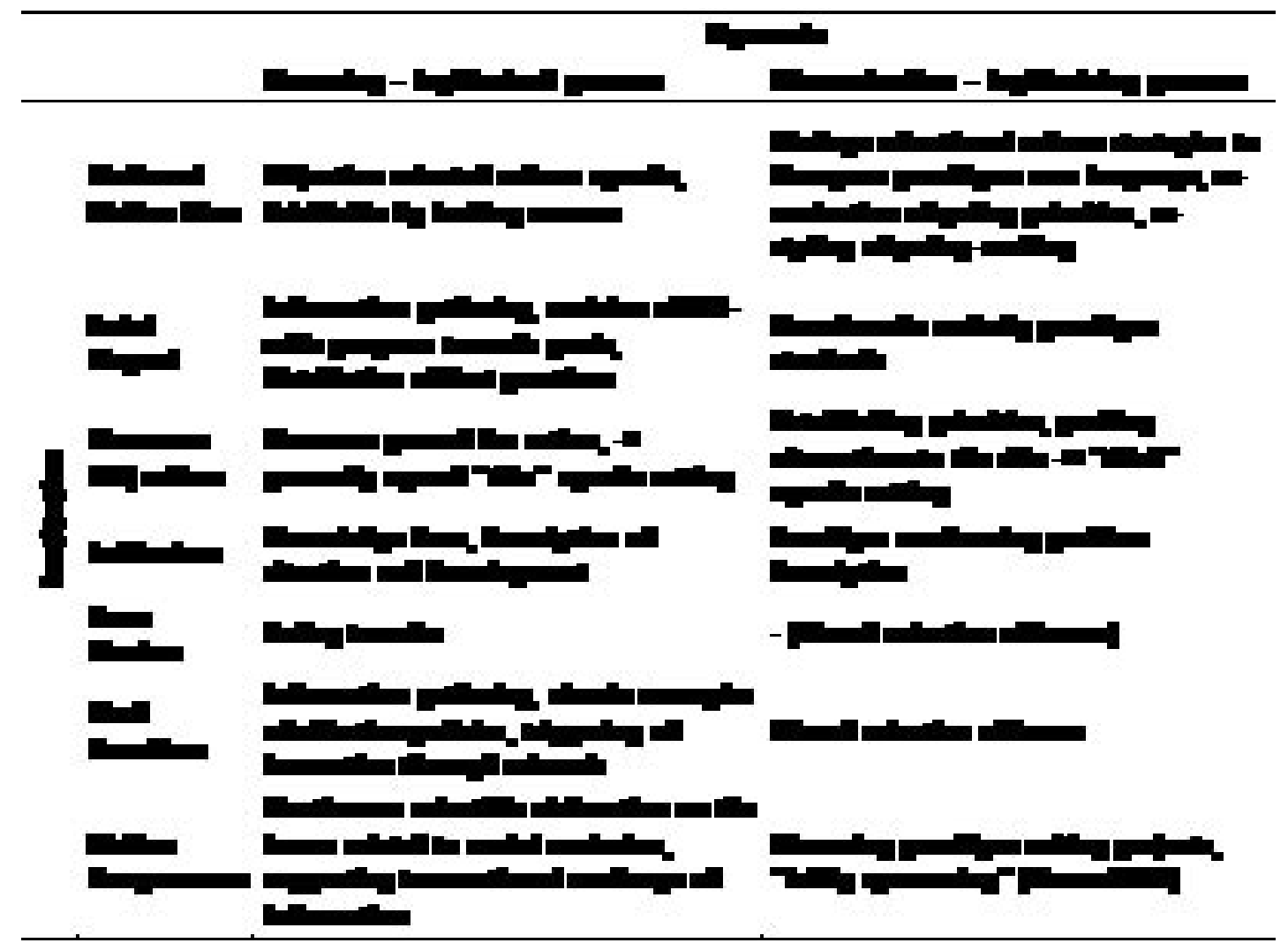


Table 2: Complex and reductionist ideal types of social exclusion

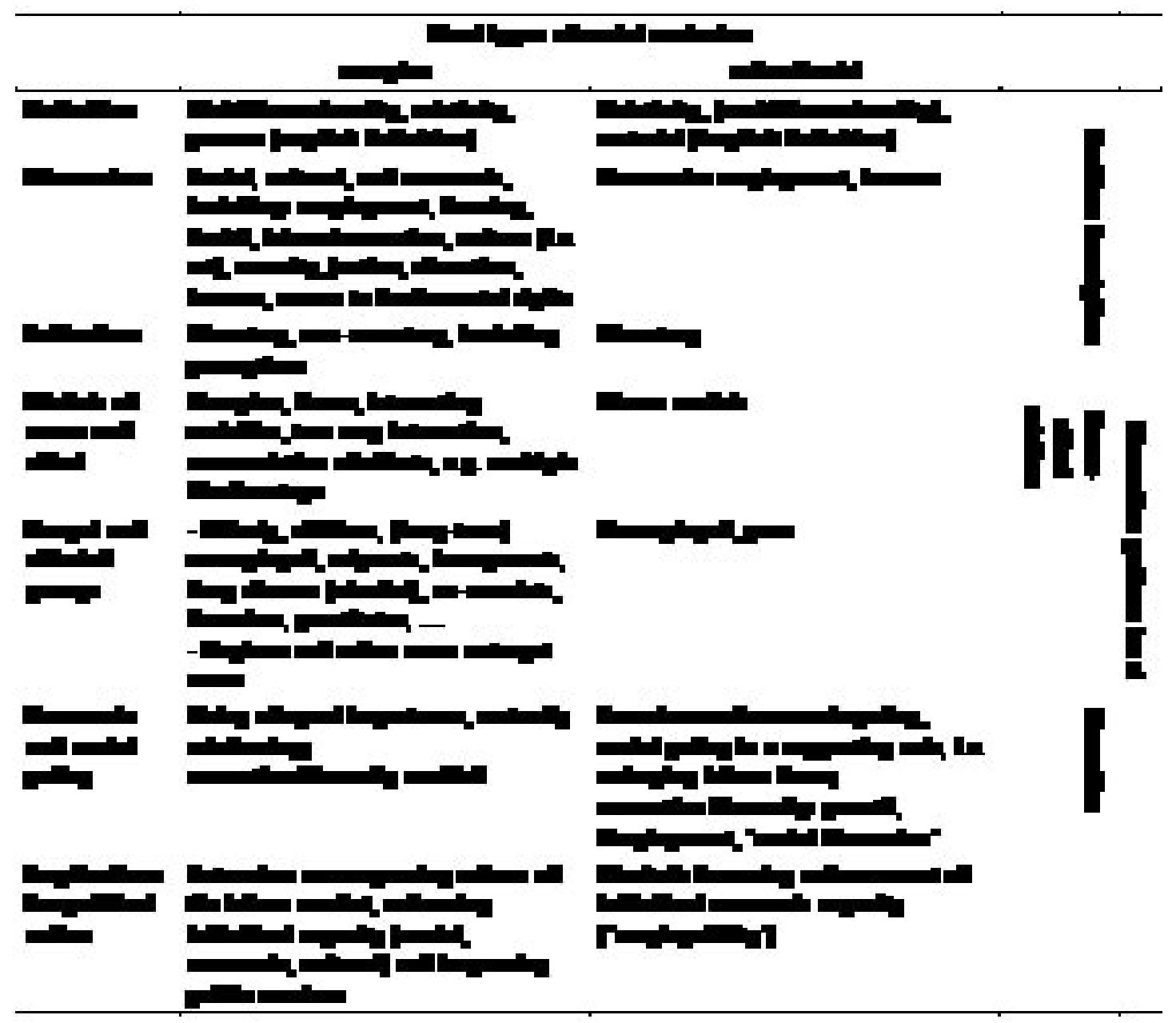


Diagram 1: The narrative pattern of the EU paradigm of social exclusion

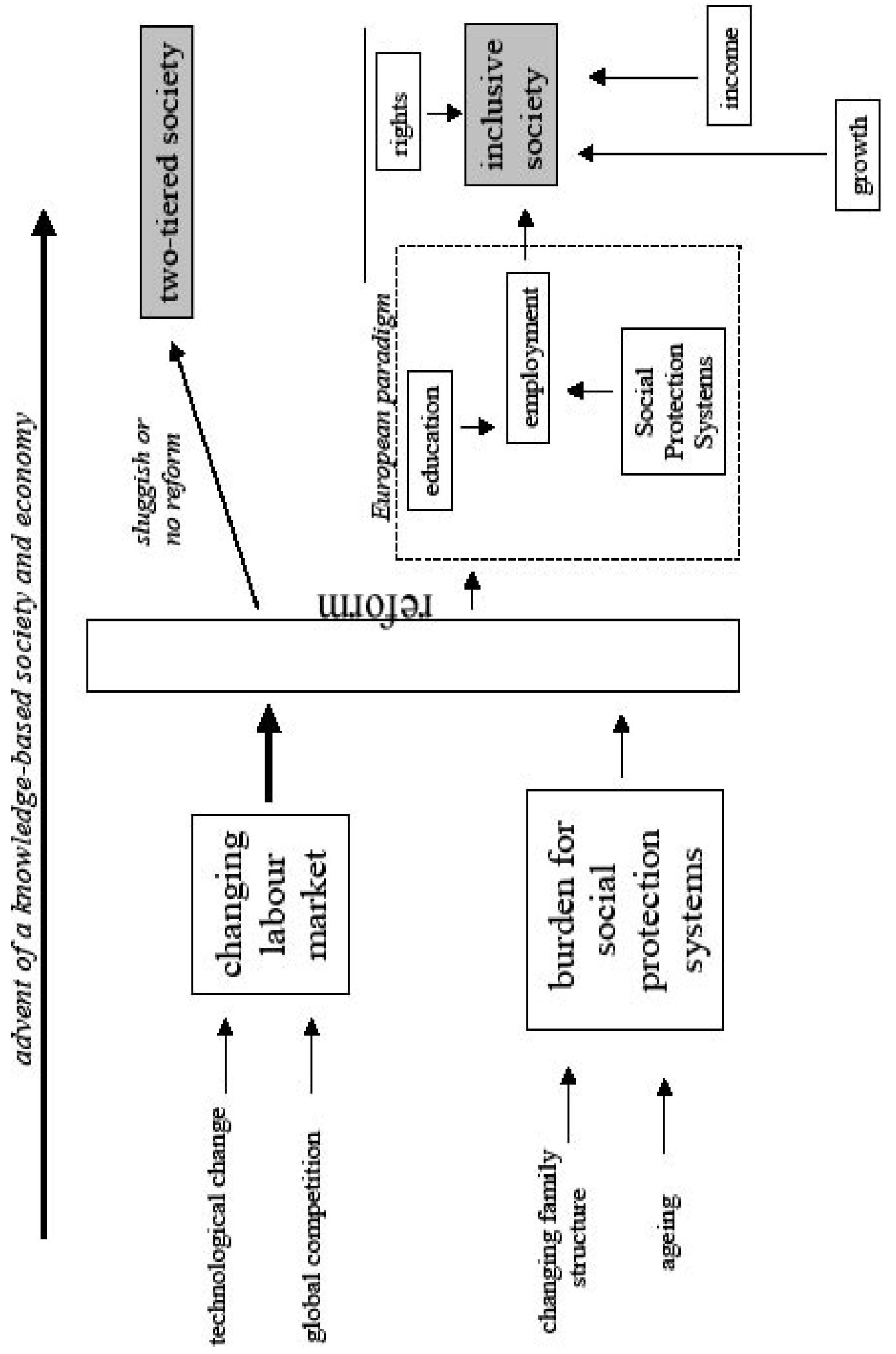

